\title{
A Special Tribute to David A. Swinney, Ph.D.
}

\author{
Edgar Zurif
}

Published online: 5 April 2009

(C) Springer Science+Business Media, LLC 2009

David Swinney was not always brilliant in dealing with publishing deadlines, and the valuable data he collected sometimes remained unpublished for rather long periods. But the problem was far from a complete paralysis-when prodded sufficiently, he responded. And the result was a body of published research of stellar quality. Indeed, the work he did publish, most often in collaboration with students and colleagues, guarantees him an important place in the history of psycholinguistic research.

Here is what he contributed: In the 1970s using the technique of cross-modal lexical decision (that he invented) he provided the basis of an unexpected perspective on the functional layout of the language comprehension system: he showed that the access of lexical information was uninfluenced by context and rational considerations - a demonstration that was incorporated into the "modularity thesis" by Jerry Fodor. Starting in the late 80s, Swinney's work focused on the mandatory and fast-acting nature of linguistic information access devices. In a study involving what was then a timing measure of exceptional precision, he and his colleagues were the first to show the real-time linkage between "moved" constituents and the gaps left by their movement. This initial research served to align developments in linguistic theory with real-time parsing considerations. And the many follow-up studies that he carried out collaboratively illuminated the general distinction between linguistic representations that are formed automatically and mandatorily and those tied to statistical bias and pragmatic knowledge. Moreover, throughout his career, he sought to discover the neuroanatomical underpinnings of these automatic information activation processes. Focusing on aphasic patients, Swinney and his colleagues (me included) uncovered the relation between disruptions to early-stage lexical access devices and the syntactic limitations attendant upon left-anterior brain damage — a discovery that he later sought to refine via fMRI.

David Swinney and his wife Emmanuelle were dear friends (she still is). We shared many good times together both in the states and here in France. I miss him. 